\title{
Tricho-Hepato-Eenteric Syndrome: Same Genotype but Different Phenotypes in Two Pakistani Children
}

\author{
Nadia Waheed, Anjum Saeed and Huma Arshad Cheema \\ Department of Pediatric Gastroenterology and Hepatology, The Children's Hospital \& Institute of Child Health, Lahore, Pakistan
}

\begin{abstract}
Tricho-hepato-enteric syndrome (THES) is characterised by infantile diarrhea with characteristic facies, trichorrhexis nodosa and hepatic involvement. The underlying genetic mutation is in tetratricopeptide repeat domain 37 (TTC37) gene. It is a very rare syndrome and only 44 cases have been reported so far in the medical literature. We recently diagnosed two children with THES on genetic analysis, who had same genotype but different phenotypes. Using these cases as a precedent, we reviewed what is known about this rare syndrome, as well as the novelties in our cases and treatment options.
\end{abstract}

Key Words: Chronic diarrhea, Liver disease, Genetic mutation, TTC37.

How to cite this article: Waheed N, Saeed A, Cheema HA. Tricho-Hepato-Eenteric Syndrome: Same Genotype but Different Phenotypes in Two Pakistani Children. J Coll Physicians Surg Pak 2022; 32(02):242-246.

\section{INTRODUCTION}

Tricho-hepato-enteric syndrome (THES) is a rare condition that affects the hair, liver, and intestines. It is manifested by intractable diarrhea that usually begins during the first six months after birth and leads to failure to thrive. The liver involvement in the affected individuals is variable ranging from cirrhosis to mild hepatomegaly with or without liver dysfunction. The syndromic children usually have characteristic hairs, trichorrhexis nodosa and typical facies as broad forehead, small mouth, low-set ears and uplifted tip of nose. ${ }^{1}$

THES is an autosomal recessive disorder, caused by mutations in TTC37 gene, located on chromosome $5 q 15 .{ }^{2}$ Other names given to this condition are phenotypic diarrhea, syndromic diarrhea, and THE syndrome. Intractable diarrhea is managed with parenteral nutrition, despite of which, affected individuals are shorter than their peers. Generally, hepatic involvement contributes to the poor prognosis. ${ }^{3}$

We present two cases diagnosed as THES on genetic analysis, having different phenotypes but samegenotype.

Correspondence to: Dr. Nadia Waheed, Department of Pediatric Gastroenterology and Hepatology, Children's Hospital and Institute of Child Health, Lahore, Pakistan E-mail: drnadiasalman@gmail.com

Received: April 28, 2020; Revised: October 19, 2020;

Accepted: October 21, 2020

DOI: https://doi.org/10.29271/jcpsp.2022.02.242

\section{CASE 1:}

An 11-year boy was referred to Pediatric Gastroenterology and Hepatology Unit, for his relentless chronic diarrhea. His symptoms started with persistent diarrhea at three years of life with frequency of 5-6 stools/day of grade III-IV consistency that were bulky and foul smelling without any blood and mucus. He described abdominal distension and failure to thrive along with thesesymptoms. Therewasalso history of recurrent chestinfections (3-4 episodes per year) in the form of fever, cough and respiratory distress. There was no history of vomiting, abdominal pain, skin or nail infection and recurrent ear discharge.

For two years, he had visited local private clinics for diarrhea and was advised antiprotozoals without any improvement. He was diagnosed as celiac disease at six years of age on the basis of elevated anti-tissue transglutaminase antibodies (TTG-IgA, $167 \mathrm{IU} / \mathrm{L}$ (Normal <9 IU/L); and advised gluten-free diet. Frequent chest infections were being managed with nebulisation, antibiotics in addition to anti-tuberculosis therapy for six months with temporary improvement. He had blood transfusions over this period.

He was born full-term with low birth weight to a consanguineous couple with three other healthy siblings. He was exclusively breast fed till six months of life and complementary diet was introduced at six months. There was no history of food allergies, tuberculosis and immunodeficiency in the family. He achieved all of his developmental milestones accordingly; but he never attended school because of his chronic illness. He was fully vaccinated according to local EPI schedule.

His examination revealed a thin lean boy having angular cheilosis, clubbing, generalised dry scaly skin and bilateral pedal edema. He was well below $3^{\text {rd }}$ centiles both in his height 
and weight (107 cms and $14 \mathrm{~kg}$, respectively). He had dysmorphism in the form of broad forehead, small mouth and widely spaced eyes. He was having thin sparse easily pluckable hair (Figure 1). His systemic examination was normal except his abdominal examination, which showed enlarged liver $4 \mathrm{~cm}$ below right subcostal margin with total span of $13 \mathrm{~cm}$.

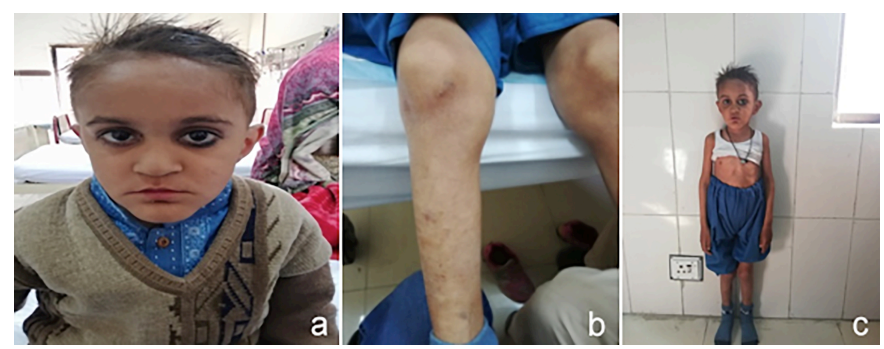

Figure 1: (a), (b) and (c): An 11-year boy with failure to thrive, abdominal distention and bilateral pedal edema. Note facial dysmorphism (hypertelorism and broad nasal root).

Laboratory workup showed microcytic hypochromic anemia and deranged liver function tests (LFTs), as shown in Table I. Alanine aminotransferase (ALT) was $121 \mathrm{IU} / \mathrm{L}$, aspartate aminotransferase (AST), $55 \mathrm{IU} / \mathrm{L}$, and alkaline phosphatase (ALP), $1231 \mathrm{IU} / \mathrm{L}$. Prothrombin time (PT) was 19/14 seconds, which was corrected with vitamin K later on. Serum albumin was $2.1 \mathrm{~g} / \mathrm{dl}$. His immunoglobulin levels were normal except for immunoglobulin G (IgG), which was $205 \mathrm{mg} / \mathrm{dl}$ (normal >500 mg/dl), which could be attributed to low albumin levels. His sweat chloride test was within normal limits and delta F508 mutation was negative. Ultrasound (US) of abdomen revealed normal gut wall thickness and hepatomegaly with altered echo texture. Computed tomography (CT) chest and abdomen was unremarkable except for hepatomegaly. Esophago-gastro-duodenoscopy (EGD) and histopathology of small bowel were normal except for presence of lymphocytes in lamina propria, suggestive of non-specific duodenitis. His genetic testing solved the enigma of difficult-to-treat diarrhea, chestinfection and abnormal hair. He was found to have homozygous mutation in TTC37 gene and both parents were heterozygous for same (Figure2).

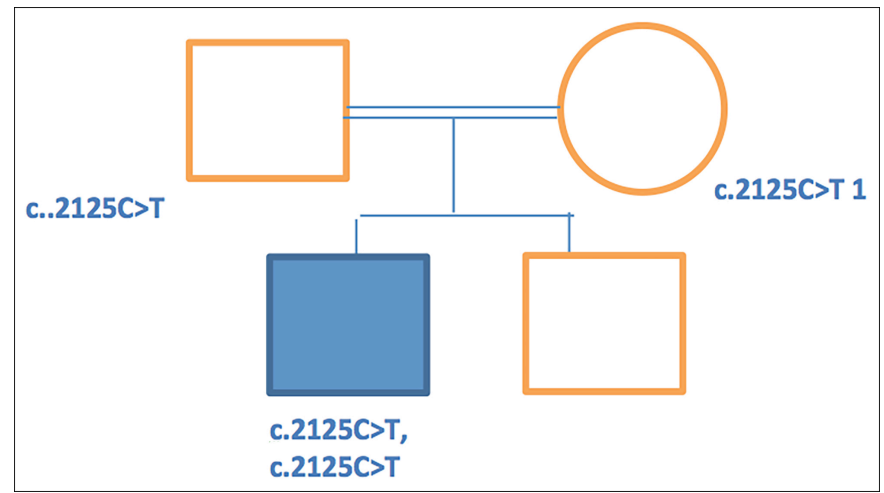

Figure 2: Pedigree of the firstcase.

We managed him with intravenous albumin, fat and water soluble vitamins and intravenous immunoglobulin (IVIG), leading to improvement in edema, dry skin, diarrhea and chest infections. He was discharged on 3-weekly IVIG; and is doing well with regularfollow-ups.

\section{CASE 2}

A 13-month Saudi-born Pakistani boy was well up to five months of life when he was admitted into hospital with bronchopneumonia for 15 days; and discharged on oral medications, but readmitted after two weeks for the same complaints and needed ventilatory support. He was discharged home on oral medications and nebulisation. At 9 months of age, he developed loose motions 8-10/day, grade III-IV in consistency without mucus and blood. On examination, he showed evidence of failure to thrive with hepatosplenomegaly, mentioned in his medical history. He was investigated for liver disease and all workup turned out to be negative except deranged LFTs. During this 9 months period, he was admitted six times for his chest problems, diarrhea and worsening liver disease, but no diagnosis could be made.

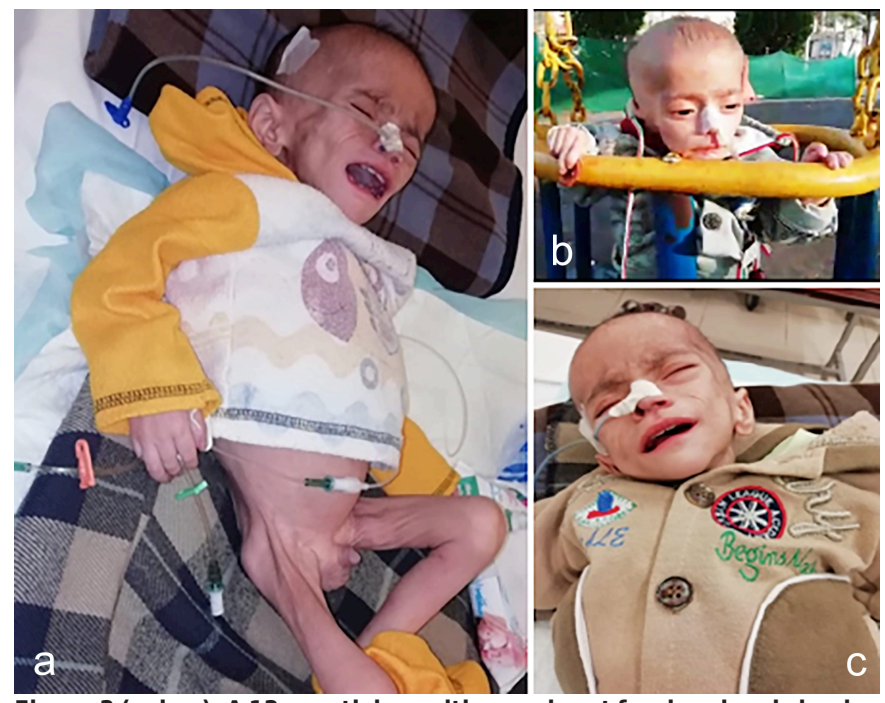

Figure $3(a, b, c)$ : A 13-month boy with prominent forehead and cheeks, hypertelorism and broad nasal root, developmental delay, failure to thrive and abdominal distention of the child.

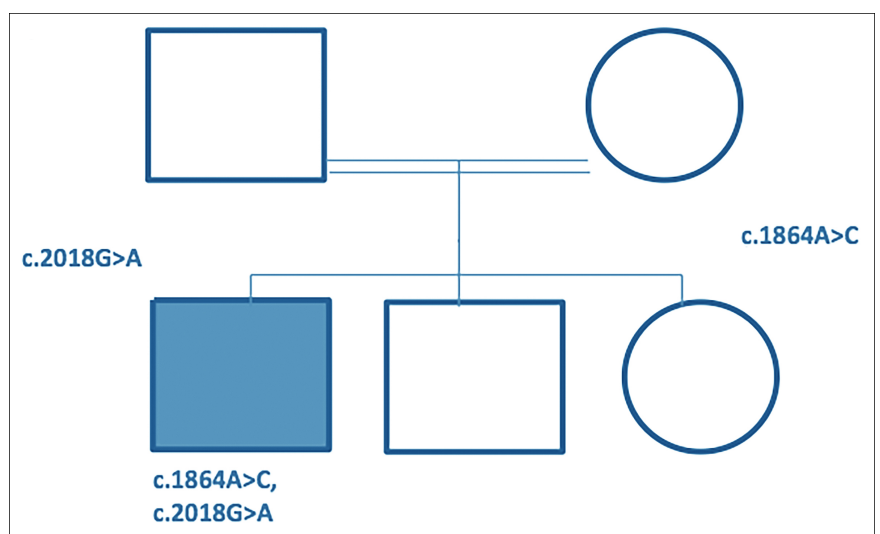

Figure 4: Pedigree of the second case.

He was born full-term to a consanguineous family with symmetrical intrauterine growth retardation (IUGR). He was exclusively breast fed till five months and topped up with formula milk because of frequent hospitalisation. The complementary food was started at 9 months of age but it could not be established adequately because of his difficult-to-treat diarrhea and lower respiratory tract infections. His development was delayed with normal hearing and vision. 
Table I: Demographic, clinical \& laboratory parameters in both cases and comparison to published literature.

\begin{tabular}{|c|c|c|c|c|c|c|}
\hline & Parameters & Case \#1 & Case \#2 & $\begin{array}{c}\text { Hartley JL et al } \\
\text { Gastroenterology, } 2010^{10} \\
(n=11)\end{array}$ & $\begin{array}{l}\text { Fabre A et al. Front } \\
\text { Immunol. } 2018^{9}(n=9)\end{array}$ & $\begin{array}{l}\text { F.E Mahjoub Case } \\
\text { Rep Pathol.2016 } \\
\qquad(\mathrm{n}=3)\end{array}$ \\
\hline 1 & Age of presentation & 3 years & 5 months & 2weeks-7months & $31(0-335)$ days & 4 months \\
\hline 2 & $\begin{array}{c}\text { Duration of symptoms } \\
\text { before diagnosis }\end{array}$ & 7 years & 8 months & 1-7 month & 3months-3years & 1-9years \\
\hline \multirow[t]{5}{*}{3} & $\begin{array}{c}1^{\text {st }} \text { symptoms at onset } \\
\text { of syndrome }\end{array}$ & Bronchopneumonia & Malabsorptive stools & Malabsorptive stools & Malabsorptive stools & $\begin{array}{l}\text { Malabsorptive } \\
\text { stools }\end{array}$ \\
\hline & Anthropo metry & $\begin{array}{l}\text { Height } \& \text { weight both } \\
\text { below } 3^{\text {rd }} \text { centiles }\end{array}$ & $\begin{array}{l}\text { Height } \& \text { weight both } \\
\text { below } 3 \text { rd centiles }\end{array}$ & - & - & - \\
\hline & Facies & yes & Yes & Yes11/11 & Yes9/9 & Yes3/3 \\
\hline & Trichorhexis nodosa & yes & Yes & Yes 11/11 & Yes9/9 & Yes $3 / 3$ \\
\hline & Visceromegaly & Hepatomegaly & Hepatosplenomegaly & $\begin{array}{c}\text { Hepatomegaly9/11 } \\
\text { hepatosplenomegaly2/11 }\end{array}$ & Hepatosplenomegaly5/9 & - \\
\hline \multirow[t]{3}{*}{4} & $\begin{array}{c}\text { Hemoglobin level at } \\
\text { presentation }\end{array}$ & $7.2 \mathrm{~g} / \mathrm{dl}$ & $6.4 \mathrm{~g} / \mathrm{dl}$ & - & - & - \\
\hline & $\mathrm{MCV}$ & $71 \mathrm{fl}$ & $62 \mathrm{fl}$ & - & - & - \\
\hline & $\mathrm{MCH}$ & $30 \mathrm{pg}$ & $28 \mathrm{pg}$ & - & - & - \\
\hline 5 & TLC & 4900/uL & $7200 / \mathrm{uL}$ & - & - & - \\
\hline 6 & Platelets count & $237,000 / \mathrm{Ul}$ & $56,000 / \mathrm{uL}$ & $\begin{array}{c}\text { Normal5/11 } \\
\text { Thrombocytosis6/11 }\end{array}$ & - & - \\
\hline 7 & ALT & $121 \mathrm{IU} / \mathrm{L}$ & $235 I U / L$ & - & - & elevated \\
\hline 8 & AST & $55 \mathrm{IU} / \mathrm{L}$ & $125 \mathrm{IU} / \mathrm{L}$ & - & - & elevated \\
\hline 9 & ALP & $1231 \mathrm{IU} / \mathrm{L}$ & $1230 I U / L$ & - & - & elevated \\
\hline 10 & STB & $0.5 \mathrm{mg} / \mathrm{dl}$ & $7.5 \mathrm{mg} / \mathrm{dl}$ & - & - & - \\
\hline 11 & Blood urea & $26 \mathrm{mg} / \mathrm{dl}$ & $22 \mathrm{mg} / \mathrm{dl}$ & & - & - \\
\hline 12 & Serum creatinine & $0.2 \mathrm{mg} / \mathrm{dl}$ & $0.3 \mathrm{mg} / \mathrm{dl}$ & - & - & - \\
\hline 13 & $\begin{array}{l}\text { Immuno globulins } \\
\text { Level }\end{array}$ & IgG Low & Normal & Low11/11 & Low6/9 & - \\
\hline 14 & Serum albumin level & & $2.3 \mathrm{mg} / \mathrm{dl}$ & - & - & - \\
\hline 15 & INR & $\begin{array}{c}\text { 1.3(Corrected with IV vit } \\
\mathrm{K})\end{array}$ & $\begin{array}{c}1.7 \text { (Not corrected with IV } \\
\text { vit K) }\end{array}$ & - & - & - \\
\hline 16 & Echo cardiography & Normal & Normal & $\begin{array}{c}\text { Normal6/11 VSD1/11 TOF1/11 } \\
\text { Al2/11 PS1/11 }\end{array}$ & Normal 9/9 & - \\
\hline 17 & Skeletal anomalies & Normal & Normal & $\begin{array}{c}\text { Normal10/11 Perthes } \\
\text { disease } 1 / 11\end{array}$ & - & - \\
\hline 18 & Renal anomalies & No & No & No10/11 small rt kidney1/11 & - & - \\
\hline 19 & Developmental delay & No & Yes & Yes7/11 No2/11 unknown2/11 & - & Yes $3 / 3$ \\
\hline 17 & Small bowel biopsy & Non specific duedenitis & Could not done & Villous atrophy $11 / 11$ & - & $\begin{array}{l}\text { Mild to moderate } \\
\text { villous atrophy } 3 / 3\end{array}$ \\
\hline 18 & Genetic mutation & $\begin{array}{l}\text { c. } 2125 \mathrm{C}>\mathrm{T} \\
\text { c. } 2125 \mathrm{C}>\mathrm{T}\end{array}$ & $\begin{array}{l}\text { C. } 1864 A>C \\
\text { c. } 2018 G>A\end{array}$ & & & \\
\hline
\end{tabular}

On examination, a cachectic child weighing $4.5 \mathrm{~kg}$ with length of $60 \mathrm{~cm}$ and fronto-occipital circumference (FOC), 45 $\mathrm{cm}$, having broad forehead, small mouth, sparse fragile hairs and was slightly icteric (Figure 3). He had tachypnea and tachycardia with nasal flaring and bilateral coarse crepitations. Abdomen was distended with liver palpable $4 \mathrm{~cm}$ below right subcostal margin and spleen $3 \mathrm{~cm}$ below left subcostal margin: both were firm in consistency without any ascites. He was admitted in intensive care unit and mechanically ventilated for his bad chest.

His laboratory data, summarised in Table I, revealed normocytic normochromic anemia with thrombocytopenia, serum ALT, $235 \mathrm{IU} / \mathrm{L}, \mathrm{AST}, 125 \mathrm{IU} / \mathrm{L}, \mathrm{ALP}, 1230 \mathrm{IU} / \mathrm{L}$, gamma glutamyl transferase (GGT), $55 \mathrm{IU} / \mathrm{L}$ serum total bilirubin (STB), $7.5 \mathrm{mg} / \mathrm{dl}$ (direct $5.5 \mathrm{mg} / \mathrm{dl}$ ) serum albumin, $2.3 \mathrm{~g} / \mathrm{dl}$ and international randomised ratio (INR) 1.7. Chest X-Ray (CXR) showed bilateral infiltrates, and ultrasonogram (USG) of abdomen revealed enlarged liver, $13 \mathrm{~cm}$ in size, with altered echotexture. His metabolic liver profile done previously showed normal urinary succinylacetone, normal galactose 1 phosphate uridyl transferase (GALT) assays and immunoglobulins levels, normal workup for lysosomal storage disorders (LSDs), and negative TORCH (toxoplasmosis, rubella, cytomegalovirus, herpes simplex) profile. His genetic analysis showed homozygous mutation in TTC37 gene, confirming the diagnosis of THES (Figure 4).

He was started on elemental formula milk and infusion of IVIG. He had improvement in diarrhea, chest infection and was weaned off from ventilator successfully. He had global developmental delay and bad liver disease. His family was counselled for poor prognosis and outcome. He was discharged home and went back to Saudi Arabia and admitted once again with lower respiratory tract infection. His liver decompensated and unfortunately he expired at 18 
months of age of liver failure.

\section{DISCUSSION}

The term THES, introduced by Verloes et al. in 1997, ${ }^{4}$ was previously known as syndromic diarrhea or phenotypic diarrhea since $1982 .{ }^{5}$ Verloes et al. described a condition affecting a brother and sister, who were born IUGR and had intractable diarrhea with normal histologic and enzymatic studies. Both had facial anomalies; included low-set ears, hypertelorism, small mouths and upturned noses along with abnormal hair texture and pattern. The sister also had cholestatic jaundice. Both siblings expired at the age of six months. Our second case had same presentation and course of illness except for his chest infections.

Recurrent chest infections are not a part of this syndrome but both of our cases had bad recurrent lower respiratory tract infections without chronic lung disease, indicating low immunity for repeated viral infections. Although immunoglobulin levels were in normal range except for low lgG levels in our first case, probably due to low albumin. Fabre et al. have reported two unrelated male infants with all prominent features of THES and humoral immunodeficiency. ${ }^{6}$

It has been mentioned in the literature that few children get bowel control as they grow older, as reported by Barabino et al. about a girl diagnosed as THES at 15 days of life who attained her bowel autonomy at one year of age and became total parenteral nutrition (TPN)-free. Intestinal histology improved, which at diagnosis showed subtotal villous atrophy. At the age of 17 years, she had severe growth delay with an adequate pubertal development, mild mental impairment, intermittent diarrhea, and frequent upper respiratory infections. It showed that if one attains bowel autonomy, this would be a good prognostic factor. ${ }^{6}$

Severe liver disease in this syndrome is a bad prognostic sign with rapid progression of the disease to liver failure. ${ }^{7}$ Our second case had severe phenotype of THES and as reported in literature, his liver involvement was a bad prognostic factor. But his severe lower respiratory tract infection needed assisted ventilation support four times, so we believe that this is also a bad prognostic factor. Moreover, in both of our cases, there was no chronic lung disease. Every time, it happened as a new acute episode, so there must be a cause other than depressed immunity behind these chest infections.

Hartley et al. reported 12 cases of THES with serially obtained histologic examination of jejunal biopsy specimens, showing that the villous atrophy can improve with age and the inflammatory infiltrates are not consistently present. $^{8}$ This was similar to our first case, but we were unable to get small bowel biopsy in our second case. He also reported cardiac anomalies in five of his cases including aortic insufficiency, peripheral pulmonary stenosis, ventricular septal defect and tetralogy of Fallot. Both of our cases did not have any cardiac anomaly as screened by multiple echocardiography examinations.

Platelet abnormalities including large platelets, thrombocytosis and on transmission electron microscopy, reduced platelet alpha-granules are present in these patients. Our second case had persistent thrombocytopenia but platelets were normal in first case. TTC37 mutation is diagnostic for this syndrome, which was detected in both of our cases. ${ }^{9,10}$

In conclusion, THES is a rare pediatric condition with facial dysmorphism, intractable diarrhea, and liver disease. Phenotype can be different in different patients with same genotype as is evident in our cases. Further insight and research is needed for managing this rare but highly morbid condition.

\section{PATIENTS' CONSENT:}

Informed consents were obtained from patients' parents to publish the data concerning this case.

\section{CONFLICT OF INTEREST:}

The authors declared no conflict of interest.

\section{AUTHORS' CONTRIBUTION:}

NW: Compiled all data, write it up and literature search.

AS: Helped in searching literature.

HAC: Helped in proofreading.

\section{REFERENCES}

1. Landers MC, Schroeder TL. Intractable diarrhea of infancy with facial dysmorphism, trichorrhexis nodosa, and cirrhosis. Pediat Derm 2003; 20(5):432-5. doi: 10.1046/j. 1525-1470.2003.20514.x.

2. Dweikat I, Sultan M, Maraqa N, Hindi T, Abu-Rmeileh S, AbuLibdeh B. Tricho-hepato-enteric syndrome: A case of hemochromatosis with intractable diarrhea, dysmorphic features, and hair abnormality Am. J Med Genet 2007; 143(6):581-3. doi: 10.1002/ajmg.a.31583.

3. Goulet OJ, Brousse N, Canioni D, Walker-Smith JA, Schmitz J, Phillips AD. Syndrome of intractable diarrhoea with persistent villous atrophy in early childhood: A clinicopathological survey of 47 cases. J Pediatr Gastroenterol Nutr 1998; 26(2):151-61. doi: 10.1097/00005176-199802000-00006.

4. Verloes A, Lombet J, Lambert Y, Hubert AF, Deprez M, Fridman $\mathrm{V}$, et al. Tricho-hepato-enteric syndrome: Further delineation of a distinct syndrome with neonatal hemochromatosis phenotype, intractable diarrhea, and hair anomalies. Am J Med Genet 1997; 68(4):391-5. doi: 10.1002/(sici)1096-8628(19970211)68:4<391::aid-ajmg3>3.0.c0;2-p.

5. Barabino AV, Torrente F, Castellano E, Erba D, Calvi A, Gandullia P. Syndromic diarrhea may have better outcome than previously reported. J Pediatr 2004; 144(4):553-4. doi: 10.1016/j.jpeds.2004.01.026.

6. Fabre A, Andre N, Breton A, Broue P, Badens C, Roquelaure B. Intractable diarrhea with 'phenotypic anomalies' and tricho-hepato-enteric syndrome: Two names for the same 
disorder. Am J Med Genet 2007; 143(6):584-8. doi: 10.1002/ ajmg.a.31634.

7. Fabre A, Martinez-Vinson C, Roquelaure B, Missirian C, Andre N, Breton A, et al. Novel mutations in TTC37 associated with tricho-hepato-enteric syndrome. Hum Mutat 2011; 32(3):277-81. doi: 10.1002/humu.21420.

8. Hartley JL, Zachos NC, Dawood B, Donowit M, Forman J, Pollitt RJ, et al. Mutations in TTC37 cause trichohepatoenteric syndrome (phenotypic diarrhea of infancy). Gastroenterology 2010; 138(7):2388-98. doi: 10.1053/j.gastro.2010.
02.010 .

9. Mahjoub FE, Imanzadeh F, Mahdavi Izadi S, Nahali Moghaddam A. Trichohepatoenteric syndrome or syndromic diarrhea-report of three members in a family, first report from Iran. Case Rep Pathol 2016; 2016:9684910. doi: 10.1155/2016/9684910.

10. Fabre A, Bourgeois P, Marie-Edith C, Roman C, Barlogis V, Badens C. Management of syndromic diarrhea/tricho-hepato-enteric syndrome: A review of the literature. Intractable Rare Dis Res 2017; 6(3):152-7. doi: 10.5582/irdr.2017. 01040. 